УДК 33(07)

DOI 10.18413/2687-0932-2020-47-2-254-263

\title{
МЕТОДИЧЕСКИЕ ПОДХОДЫ К ОЦЕНКЕ РАЗВИТИЯ РЕГИОНА С ПОЗИЦИИ ИССЛЕДОВАНИЯ УРОВНЯ ЕГО ТУРИСТСКОГО ПОТЕНЦИАЛА
}

\section{METHODICAL APPROACHES TO THE DEVELOPMENT OF THE REGION THROUGH THE STUDY OF ITS TOURIST POTENTIAL}

\author{
В.А. Столярова, 3.В. Столярова, А.С. Трошин \\ V.A. Stolyarova, Z.V. Stolyarova, A.S. Troshin
}

Белгородский государственный технологический университет им. В.Г. Шухова, Россия, 308012, ул. Костюкова, 46

Belgorod State Technological University named after V.G. Shukhov 46 Kostyukova St, Belgorod, 308012, Russia

E-mail: zlatast@mail.ru

\begin{abstract}
Аннотация
В статье рассмотрены основные принципы развития туристского потенциала как одного из ведущих индикаторов повышения конкурентоспособности региона. Были рассмотрены специфические особенности пространственного развития территорий в условиях глобализации. Обоснована необходимость создания и внедрения инвестиционных проектов, ориентированных на повышение уровня туристской привлекательности региона. В работе представлены новые методические подходы к анализу эффективности инвестиций в сферу регионального туризма, разработана система критериев их оценки с учетом группы показателей риска.
\end{abstract}

\begin{abstract}
The article presents a comprehensive study of the phenomenon of tourist potential through the construction of the author's model. Tourism potential has been explored from the perspective of the most important factor in improving the region's competitiveness. In particular, the specific features of the spatial development of the territories in the context of globalization of economic, social and cultural processes were considered. On this basis, the expediency of developing and operating investment projects aimed at increasing the tourist attraction of the region was justified. All of this requires a review of the traditional investment assessment system. For this reason, the article provides and analyzes new methodological approaches, including group of criteria for evaluating an investment project aimed at improving the level of development of the region through qualitative enhancement of its tourist capacity. In conclusion, a system of risk indicators was developed, which is necessary for the construction and implementation of the project.
\end{abstract}

Ключевые слова: туристский потенциал, инвестиционный проект, пространственное развитие, конкурентоспособность региона, риски.

Keywords: tourism potential, investment project, spatial development, competitiveness of the region, risks.

\section{Введение}

В настоящее время проблема пространственного развития территории и повышение региональной конкурентоспособности приобретает наиболее острый характер. Это обусловлено, прежде всего, естественной причиной, заключенной в бесконечном и перманентно ускоряющемся росте потребностей, и все больше истощающейся ресурсной базой, которой располагает человечество. [Столярова, 2019]. Поэтому конкурентоспособность региона должна быть дополнена весомым преимуществом, которое скрыто в его туристском потенциале. [Брусконе, 2014]. Более того, нельзя не отметить противоречивый характер 
регионального развития в силу его амбивалентности, имеющей место в результате противоборства процессов локализации и глобализации [Гареев, 2017]. Все это настоятельно требует разработки комплекса мер, направленных на раскрытие, укрепление и дальнейшее развитие туристского потенциала отдельных регионов или стран в целом.

На первом этапе необходимо уточнить понятие туристского потенциала, поскольку это оправдано не только научной целесообразностью, но и исключительным практическим значением. Смысловое дополнение категории позволит определить основные подходы к его оценке, измерению и управлению.

Исходя из этих соображений, необходимо развести формальную и содержательную природу этого понятия. Первая нацелена на изучение объекта, потенциал которого исследуется. Им может быть конкретный город, округ, провинция или страна. Субъективный анализ основывается на содержательной стороне потенциала в зависимости от задач, которые предполагается решить. Например, усилить познавательный, рекреационный или событийный компонент туристского ресурса [Святохо, 2016].

Отталкиваясь от данной аргументации, необходимо указать на различия двух понятий: туристский потенциал и туристский ресурс. Дело в том, что туристский потенциал более соотносится с содержательной стороной и определяется целями, которые необходимо достигнуть для повышения общей инвестиционной привлекательности региона. Что касается туристского ресурса, он представляется скорее комплексом исходных условий, объективно существующей базой, определяющей вероятную возможность для обеспечения конкурентоспособности территории [Сесёлкин, Рассохина, 2013]. Другими словами, какойлибо природный ресурс региона, например озеро, может использоваться одновременно и сельскохозяйственной отраслью, и промышленностью, и транспортной связью. В отношении туристского потенциала будут оцениваться только те характеристики указанного водоема, которые значимы исключительно для конкретного вида туризма. В данном случае, это будет рекреационная, спортивная или медицинская составляющая. Таким образом, анализ туристского потенциала производится с точки зрения субъективных оценочных утверждений.

Указанные доводы позволяет заключить, что понятийное поле «туристского потенциала» несколько шире «туристского ресурса», поскольку аккумулирует целый ряд диверсифицированных аспектов, которые необходимо оценить на предмет способности положительным образом влиять на конкурентоспособность региона.

Обобщая сказанное, по нашему убеждению, следует считать наиболее корректным следующее определение термина «туристский потенциал региона»: туристский потенциал региона представляет собой комплекс факторов, имеющих место на отдельно взятой территории, обуславливающих возможность развития туристской индустрии с получением дальнейшего положительного социально-экономического эффекта.

\section{Объекты и методы исследования}

Туристский потенциал следует интерпретировать как динамичную многоаспектную систему, составные части которой находятся в постоянном взаимодействии. При этом имеют место непрерывные модификационные процессы, адаптирующие ее к постоянно меняющимся запросам рынков [Nasir, 2019]. Таким образом, происходит постоянная трансформация внешних и внутренних состояний, предопределяющая возможный переход потенциала в качественно новую форму. То есть, другими словами, положительный эффект от туристского потенциала будет определяться степенью гибкости и масштабируемости входящих в него элементов, способных развиваться сообразно имеющим место конъюнктурным данным.

В зависимости от масштаба исследования, туристский потенциал можно рассматривать как систему всех ресурсов, комплексно определяющих туристскую привлекательность территории или же вычленить и проанализировать отдельные его аспекты более детализировано. В последнем случае, как правило, подразумеваются следующие компоненты туристского потенциала:

- природный компонент, означающий совокупность всех экологических факторов;

- экономический компонент, учитывающий материальные и трудовые ресурсы региона; 
- социальный компонент, учитывающий жизненные условия местного населения, этнические и бытовые особенности, лояльность жителей к туристам и др.;

- технический компонент, определяющий возможность размещения туристов и степень удовлетворения их потребностей;

- культурно-познавательный компонент, включающий наличие объектов культуры и искусства, способных усилить привлекательность региона.

Следует отметить, что современные реалии глобализации накладывают дополнительные трудности на проблему формирования устойчивого туристского потенциала территории [Куприянов, Столярова, 2015]. В мире, где информация доступна в любой момент и распространение происходит молниеносно, очень сложно поддерживать должный уровень конкурентоспособности региона в общем и его туристской привлекательности в частности. Более того, ситуацию дополнительно усложняет скорость изменения вкусов и предпочтений потребителей туристского продукта. Так, например, некогда мегапопулярные пакетные туры по системе «все включено» уступают место самостоятельному планированию направления поездки, бронированию отеля и покупке авиабилета. А стандартные экскурсионные туры считаются скучной альтернативой модному направлению индивидуального туризма на лоукостерах и автостопом с одним рюкзаком. Происходит переориентация дестинаций, и такие привычные и вечно переполненные путешественниками Средиземноморские курорты, европейские столицы и белоснежные пляжи юго-восточной Азии постепенно сдают свои позиции перед экзотическими джунглями Центральной Африки, пампасами и вулканами Южной Америки или даже суровыми снежными пустынями Антарктиды. Путешествие становится теперь не просто комфортным и приятным украшением будничной рутины, а вызовом обществу и самому себе, а также поиском мест, запечатление которых может поразить искушенных подписчиков в соцсетях. Более того, все большее количество людей вовлекаются в систему каучсерфинга, подразумевающую полное погружение в быт, культуру, социальную жизнь другой страны или региона. Эти новые тенденции привносят качественные и порой неожиданные изменения в традиционные схемы пространственного развития. Другими словами, страны с развивающейся экономикой, отстающие технически и социально, начинают заявлять о своем солидном туристском потенциале. С одной стороны, для таких государств возможность привлечения туристов - прекрасный шанс не только поддержать отрасли, связанные непосредственно с туризмом, но и улучшить общее благосостояние населения и количественно повысить макроэкономические показатели страны. С другой стороны, организация туров в нетрадиционные и экзотические направления сопряжена с дополнительными рисками, которые не могут не учитываться организаторами поездок, продающими турпродукт или самостоятельными путешественниками, планирующими поездку.

В отношении территорий идет постоянная конкурентная борьба за утверждение преимущества своего потенциала [Мухаметова, 2016]. Регионы, при непосредственном участии продавцов турпродукта (турагентств, туроператоров), покупателей (путешественников и курортников), инфраструктурных объектов, природных ресурсов, общего социального, политического и экономического фона формируют собственный туристический имидж территории. В этой связи нельзя не отметить, что деятельность по улучшению привлекательности региона для туристов способствует дополнительному притоку инвестиций и положительным образом влияет на состояние смежных отраслей: транспорта, строительства, коммуникаций, связи, розничной торговли и сельского хозяйства. То есть имидж региона, обусловленный, допустим, исключительно природными факторами (например, существованием какого-нибудь уникального водопада), способствует развитию инфраструктуры развлечений и общественного питания, что в свою очередь делает необходимым развитие сельского хозяйства, строительства и транспортной системы, и далее последовательно поднимает уровень технического и технологического потенциала [Матвеев, Степанова, 2017]. Таким образом, комплекс взаимосвязанных факторов, который представляет собой туристский потенциал, является гибкой системой, демонстрирующей постоянное развитие. В связи с этим необходимо исследовать возможности раскрытия 
туристского потенциала, как важнейшего фактора регионального развития [Dankova Z.Y., Muzyleva E.S., 2017]. В большинстве случаев повышение туристской притягательности какойлибо территории невозможно без притока инвестиций. Поэтому, на наш взгляд, основная задача - это оценить их эффективность посредством реализации проекта, оценка перспективности которого требует разработки новых методологических подходов, подразумевающих специфические критерии при учете возможных рисков.

\section{Результаты и их обсуждение}

В деле пространственного развития региона туристскому потенциалу отводится значительное место, поскольку он является драйвером конкурентоспособности и перспективной базой для процветания территории. Вследствие этого, по нашему убеждению, необходимо определить принципы формирования и развития туристского потенциала.

1. Принцип комплексности, который предполагает активацию совместной деятельности всех хозяйствующих субъектов, участвующих в создании и продвижении туристского продукта. В этом случае прямыми фигурантами указанной деятельности будут туроператоры, турагентства, представители гостиничного бизнеса, предприятия общественного питания, устроители досуга, транспортные компании, точки розничной торговли, экскурсионные бюро. Что касается косвенных субъектов, к ним можно отнести банки и обменные пункты, транспортные терминалы, операторов связи, лечебные учреждения, органы правопорядка, а также работников консульств и посольств. Скоординированность действий указанных структур является важнейшим условием развития туристского потенциала региона.

2. Принцип планирования, который предусматривает составление и внедрение планов развития туризма при обязательном их включении во все значимые общественные сферы: образование, здравоохранение, спорт, наука, культура и искусство.

3. Принцип инновационного развития. Он базируется на идее продвижения инновационной составляющей туризма, без которой невозможно повышение конкурентоспособности региона. Это подразумевает разработку новых технологий в сфере турбизнеса и смежных с ним отраслях, активное использование уже созданных новаций и их адаптация к имеющейся научно-технической базе [Столярова, 2019].

4. Принцип стимулирования деловой активности. Прежде всего этот принцип затрагивает сферу малого бизнеса, но вместе с тем происходит поступательное подключение крупных компаний, которые опосредованно участвуют в создании положительного имиджа территории. К ним можно отнести крупные гостиничные сети, авиакомпании, строительные девелоперские группы и другие.

5. Принцип всестороннего распространения. В этом случае имеется в виду международное сотрудничество и развитие обоюдовыгодных связей между различными странами в области технологий, культуры, науки, спорта и т. д.

6. Принцип локальной защищенности. Этот принцип предусматривает мероприятия по обеспечению безопасного и комфортного проживания не только туристов, но и учет интересов местного населения. При правильной организации соблюдение этого принципа будет способствовать повышению общего уровня гостеприимства и позволит избежать недовольства и протестов со стороны коренного населения в отношении избыточного потока туристов, как это происходит в Барселоне или Венеции.

7. Принцип экологичности включает учет рисков, связанных с нарушением природного ландшафта, неэффективного использования естественных ресурсов, а также принятие комплекса превентивных мер по их устранению

8. Принцип профилактики конфликтов. Имеются в виду, прежде всего, межэтнические, религиозные конфликты, проявление расовой нетерпимости, демонстрация любых форм дискриминации.

Обозначенные принципы позволят создать методологическую основу управления конкурентоспособностью региона, основанную на развитии его туристского потенциала. Наиболее важными методами среди прочих, по нашему мнению, являются: 
1. обеспечение безопасности жизни и психологического комфорта туристов посредством скоординированной и оперативной работы правоохранительных органов;

2. защита законных прав иностранцев и местных граждан через укрепление правовой базы при соблюдении международных юридических норм;

3. контроль качества и безопасности товаров и услуг, производимых отраслями, связанными со сферой туризма;

4. обеспечение здоровой конкурентной среды посредством комплекса соответствующих антимонопольных мероприятий;

5. правовая защита экономических интересов предпринимательства, прямо или косвенно вовлеченного в процесс создания туристского продукта;

6. составление плана мероприятий по экологической защите и охране памятников культуры и искусства;

7. повышение качества информационного обеспечения в целях повышения значимости туризма для физического, интеллектуального и духовного развития населения;

8. обеспечение политической, экономической и социальной стабильности, что является непременным условием создания положительного имиджа региона;

9. продвижение и защита национальных интересов в рамках международного сотрудничества в сфере туризма.

Эти и другие методы должны быть реализованы при содействии федеральных и региональных органов управления в границах целевых программ, разработанных в ключе базовых принципов пространственного развития [Malykhina I.O, 2017]. Вместе с тем наиболее действенным методом повышения туристской привлекательности региона является внедрение инвестиционных проектов с соответствующей ориентацией [Дорошенко, Сомина, 2015].

Любой вариант инвестиционной деятельности сопряжен с большей или меньшей степенью риска [Кузнецов, 2014]. В случае, если речь идет о туристском потенциале, список рисков значительно расширяется в силу значимости различных факторов политического, культурологического, социального, религиозного и юридического плана. Столь динамично развивающаяся отрасль народного хозяйства, как туризм требует особой формы инвестиционной деятельности, что, в свою очередь, говорит о необходимости качественного пересмотра традиционных подходов к оценке эффективности инвестпроекта. Таким образом, можно утверждать, что экономическая эффективность проекта в сфере туризма универсальный показатель, позволяющий установить степень результативности и целесообразности деятельности, направленной на количественный и качественный прирост факторов, определяющих туристский потенциал региона.

Генеральная цель инвестиционной деятельности в сфере туристического бизнеса состоит в максимизации прибыли владельцев инвестиций, часть которой обязательно найдет отражение в состоянии общего благосостояния субъектов и объектов, связанных прямо или косвенно с проектом. Это означает конвертацию личной выгоды владельца инвестиций и организатора проекта в улучшение общего имиджа территории с точки зрения туристической привлекательности.

Любой инвестиционный проект принимает во внимание три основных фактора: доходность, время и риск [Дорошенко, Сомина, 2013]. Однако в случае с туристским потенциалом, их количественная интерпретация может быть затруднена в силу существования дополнительных рисков. Существующие методики оценки применительно к проекту, нацеленному на повышение регионального турпотенциала, позволяют составить приблизительное представление о его будущей рентабельности и могут служить скорее информацией к размышлению, а не четким руководством к действию. Поэтому, признавая безусловную научную и практическую значимость традиционных методологических подходов, считаем необходимым разработку новой методики оценки.

Данный методический подход может быть разложен на соответствующие этапы, последовательно включающие постановку цели, построение алгоритма методики, отбор показателей, необходимых для оценки эффективности проекта, и, наконец, вывод интегрального показателя оценки. 
Первый этап подразумевает установление цели, которая должна быть достигнута по завершении реализации проекта. Общая миссия, заключающаяся в повышении туристского потенциала региона, должна конкретизироваться задачами, учитывающими способы минимизации издержек, достижение коммерческой эффективности или создание новых инфраструктурных объектов, способных усилить туристическую привлекательность территории. В этом заключается подготовка алгоритма методического подхода.

Далее происходит этап отмежевания основных показателей, способных оценить социальную и экономическую целесообразность проекта, его соответствие запросам общества на данном этапе. Причем социальная эффективность первична перед коммерческой, поскольку общественно несостоятельный проект не сможет найти финансовой поддержки ни на частном, ни на государственном уровне. Коммерческая эффективность не только связана с вопросами финансирования, она должна учитывать территориальную, национальную и культурологическую специфику. Именно поэтому интегрирующий показатель демонстрирует многоуровневую систему оценки эффективности инвестпроекта, совмещая следующие аспекты: внутриорганизационная эффективность, отраслевая эффективность, хозяйственная эффективность, бюджетная эффективность.

В ходе разработки инвестиционного проекта, главной целью которого является повышение туристического потенциала региона, производится аналитическая работа по нескольким направлениям одновременно, что отражено на рисунке 1.

Необходимо отметить, что оценка инвестпроекта в сфере туристического бизнеса может носить значительную степень неопределенности в силу изменчивости различного рода условий и существования множества рисков, связанных с социальной, политической, культурно-этнической конъюнктурой [Куприянов, Трошин, 2016]. Именно поэтому целесообразно провести комплексное исследование условий, определяющих туристский потенциал территории, учитывая в том числе макроэкономические показатели конкретной страны, уровень гостеприимства местного населения, эпидемиологическую, экологическую и криминогенную обстановку, особенности местного законодательства, специфику отношений предпринимательского класса и институциональных структур, емкость местного рынка и ряд других.

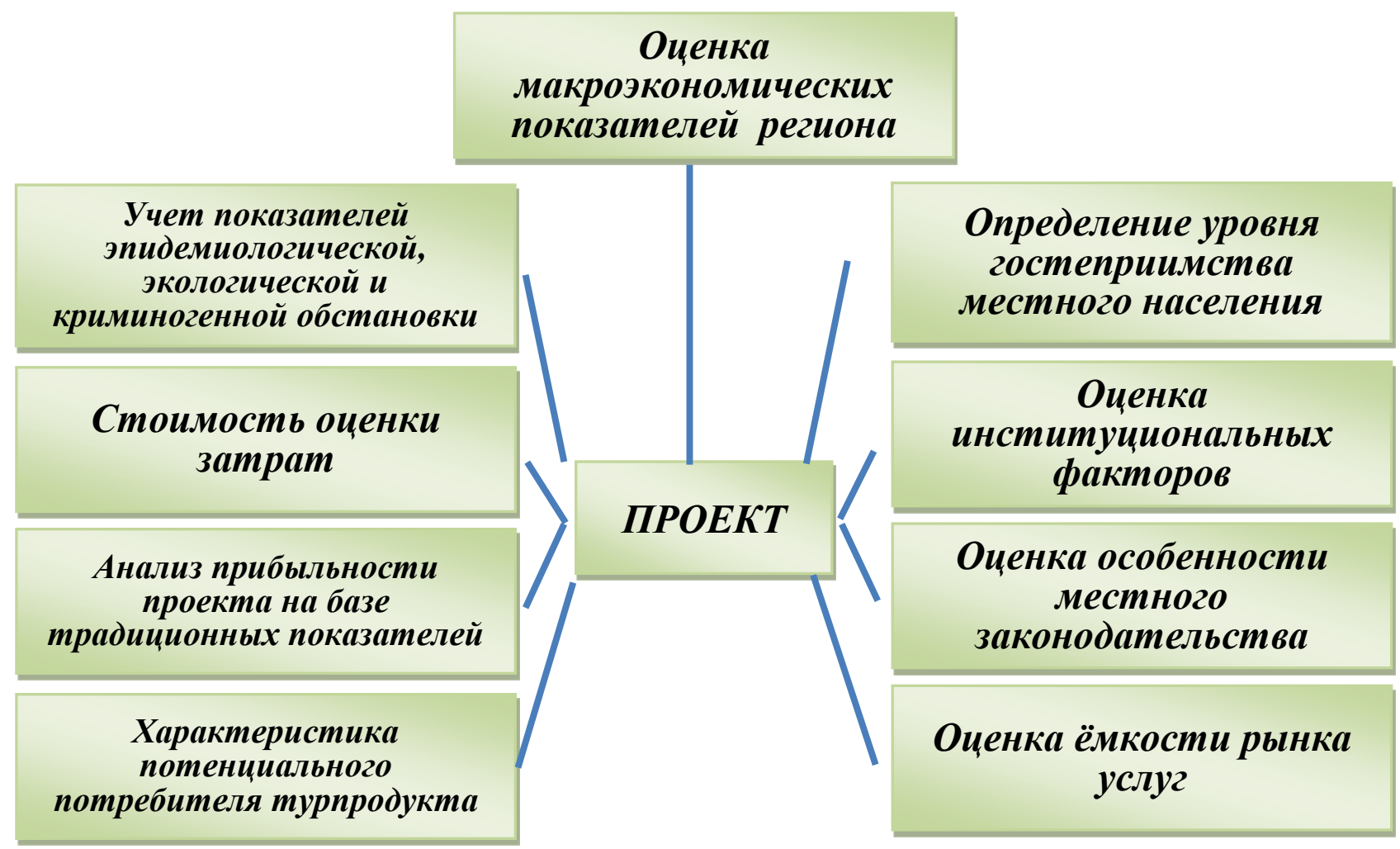

Рис. 1. Компоненты оценки эффективности инновационного проекта в сфере туризма

Fig. 1. Components for evaluating the effectiveness of an innovative tourism project 
Объективность оценки инвестиционного проекта будет зависеть от возможности модифицирования традиционных методологических подходов. На наш взгляд, этому требованию более всего соответствуют методики, подразумевающие дисконтирование денежных потоков, а именно метод определения внутренней нормы прибыли и метод чистой текущей стоимости [Кузнецов, 2014]. Указанные подходы позволяют корректировать оценку, добавляя количественные и качественные показатели, а также учитывают инфляционный момент. Безусловно, подобная оценка должна быть дополнена инструментом учета возможного риска.

В рамках методики была предложена система факторов, определяющая наличие и степень риска по отдельным группам:

Группа социальных факторов рисков: уровень гостеприимства местного населения, статистика преступности, случаи терроризма, эпидемиологический фон, языковой барьер, культурные, религиозные особенности.

Группа экологических факторов рисков: сезонные погодные явления, частота стихийных бедствий, безопасность в сфере общепита, санитарные условия общественных мест, качество воды, состояние воздуха.

Группа экономических факторов рисков: уровень подготовки персонала, задействованного в туристической сфере и смежных отраслях, волатильность спроса, рост налогов, платежеспособность местных жителей и туристов, показатели инфляции, уровень развития транспортной системы.

Политические факторы риска: устойчивость политического режима, отношение властей и бизнеса, частота массовых выступлений, характер народных протестов, вероятность наступления военных действий, политическая обстановка в соседних странах.

В процессе оценки рисков целесообразно произвести процедуру взвешивания, определив приоритеты. Интегральная оценка будет демонстрировать общую степень риска, а начисление приоритетов и весов позволит спланировать профилактические мероприятия по снижению негативных факторов.

Для этого, прежде всего, следует определить экспертную оценку риска по отдельным категориям (ORк):

$$
\text { ORK }=\sum_{i=1}^{m} \ni K_{1} \beta_{i}+\sum_{i=1}^{m} \ni K_{2} \beta_{i}+\ldots+\sum_{i=1}^{m} Э K n \beta_{i}
$$

где ЭКn - оценка каждого из экспертов, $\beta$-вес каждого фактора по отдельным категориям, $\mathrm{n}$ число экспертов, $\mathrm{m}$ - количество факторов по каждой категории. Таким образом, мы можем получить оценку риска всех экспертов по каждой категории:

Зная суммарную экспертную оценку по отдельным категориям и число экспертов, мы можем определить среднюю оценку риска по каждой категории:

$$
\mathrm{R}_{\mathrm{cp}}=\text { ORK / } \mathrm{n} \text {. }
$$

Таким образом, совокупную оценку риска (SOR) можно рассчитать по формуле:

$$
\mathrm{SOR}=\mathrm{JR}_{\mathrm{cp} .}+\mathrm{CR}_{\mathrm{cp} .}+\ni_{\mathrm{K}} \mathrm{R}_{\mathrm{cp} .}+\Pi_{\mathrm{cp}},
$$

где $Э R_{\text {cp. }}$ - средняя оценка риска экологических факторов, $\mathrm{CR}_{\mathrm{cp} .}-$ средняя оценка риска социальных факторов, $Э_{\text {к }} R_{\text {cp. }}-$ средняя оценка риска экономических факторов, $\mathrm{R}_{\mathrm{cp} .}-$ средняя оценка риска политических факторов.

Предельное значение суммарного риска, по нашему мнению, должно стремиться к минимуму или, по крайней мере, не превышать 0,5 , поскольку более высокий результат делает риск неоправданным.

Общее значение совокупной оценки будет меняться в зависимости от состава участников экспертной группы, а также определений приоритетов учитываемых факторов, которые подвержены влиянию рыночной и социально-политической конъюнктуры, и в целом будут отличаться по странам и регионам. Вместе с тем, несмотря на высокую степень 
субъективности, которая всегда присутствует в экспертном анализе, совокупная оценка риска позволяет существенно скорректировать прогнозы относительно рентабельности проекта.

Таким образом, применяя традиционные методики оценки инвестиционной эффективности проекта в сочетании с расчетом показателя совокупного риска, мы можем ввести дополнительные опции, позволяющие детализировать оценку эффективности инвестиций проекта, направленного на повышение туристского потенциала региона.

В конечном счете, можно резюмировать следующие принципы оценки:

- необходимость определения целесообразности осуществления инвестиционного проекта на протяжении всего его жизненного цикла с учетом времени и инфляции;

- расчет прогнозируемых доходов и расходов, исходя из их настоящей ценности с начала запуска инвестиционного проекта и на протяжении всего времени его действия посредством метода дисконтирования денежных потоков;

- определение суммарного показателя риска;

- учет и анализ косвенных факторов, корректирующих показатели эффективности в зависимости от специфики туристского потенциала отдельно взятого региона;

- прогнозирование отрицательных и положительных воздействий проекта на отрасль туризма, смежные отрасли и конкурентоспособность региона.

\section{Выводы}

Пространственное развитие территорий является одним из самых значимых условий повышения конкурентоспособности национальной экономики. Особенно это необходимо для стран с четко выраженными тенденциями к централизации, в условиях которых происходит отток трудовых, финансовых и технологических ресурсов из удаленных областей. В результате наблюдается структурная деформация экономики, неравномерность регионального развития, и как следствие, усиление социальной дифференциации. По этим соображениям необходимо уделять особое внимание перспективному развитию периферийных территорий. Одним из факторов роста региональной конкурентоспособности является формирование и укрепление туристского потенциала, поскольку последний предоставляет широкую базу для успешного функционирования многих отраслей, прямо или косвенно участвующих в процессе создания туристского продукта. Туристский потенциал является драйвером роста совокупного спроса, увеличения числа промышленных предприятий, разрастания социальной инфраструктуры, притока новых технологий, увеличения числа высококвалифицированных специалистов.

Формирование туристского потенциала должно происходить на базе ряда принципов, большинство из которых были рассмотрены выше. Более того, необходимо подчеркнуть, что повышение уровня туристского потенциала невозможно без реализации инвестиционных проектов. Любой инвестиционный проект должен быть оценен с позиции его эффективности, однако в случае с туристической сферой традиционные методики оценки должны быть скорректированы в силу существования различных категорий рисков.

Таким образом, на наш взгляд необходимо модифицировать методологические подходы к оценке инвестиционной эффективности проекта, направленного на повышение туристского потенциала и разработать интегральный показатель рисков, оцененных с помощью экспертной оценки, основанной на назначении весов и приоритетов.

\section{Список литературы}

1. Брусокене Т.В. 2014. Формирование и реализация туристского потенциала региона: Автореф. дис. ... канд.. экон. наук, Санкт-Петербург, 18.

2. Гареев И.Ф., Мухаметова Н.Н. 2017. Комплексное развитие территорий: цели, ресурсы и показатели эффективности. Российское предпринимательство, 18(23): 3939-3952.

3. Кузнецов Б.Т. 2014. Управление инвестициями. М., Благовест-В, 425.

4. Матвеев Ю.В., Степанова Т.Е., Матвеев К.Ю. 2017. Региональное развитие как инновационно-инвестиционный процесс институционального управления. Креативная экономика.11(5): 637-658. 
5. Мухаметова Н.Н. 2016. Территориальный подход к формированию конкурентных преимуществ региона. Жилищные стратегии. 3(3): 179-192.

6. Святохо Н.В. 2016. Концептуальные основы исследования туристского потенциала региона. Теория и практика управления, 2: 30-35.

7. Сесёлкин А.И., Рассохина Т.В. 2013. Анализ критериев устойчивого развития туристских дестинаций. Научно-практический журнал «Вестник РМАТ». 2(8):28-33.

8. Столярова 3.В., Столярова В.А., Панго Чапдо Седоин. 2019. Наука и технологии как важнейший фактор экономического развития в условиях глобализации. 6th International Conference Law, economy and management in modern ambience lemima, Univerzitet „Union - Nikola Tesla”, Beograd: 313-317.

9. Dankova Z.Y., Muzyleva E.S. 2017. Modeling of managerial processes in the conditions of innovative economy. Adavnces in Engineering Reeseach. (Actual Issues of Mechanical Engineering AIME 2017), 133: 148-155.

10. Doroshenko Y.A., Somina I.V., Komissarov S.A. and Doroshenko S.Y. 2015. The Essence and Characteristics of Investment Processes in Small Innovative Enterprises. Asian Social Science 11(6):185-191

11. Doroshenko Y.A., Somina I.V., and Komissarov S.A. 2013. Sources of Financing and Innovative and Investment Activity of Small Enterprises. World Applied Sciences Journal 25(6): 975-982

12. Kupriyanov S.V., Troshin A.S., Sandy I.S., Stryabkova E.A. 2016. Investment process development: principles and characteristics. International Journal of Pharmacy and Technology, 8. (4): 2484824855 .

13. Kupriyanov S.V., Stolyarova V.A., Stolyarova Z.V. 2015. The role of science as a factor of integration of countries in the context of globalization. Asian Social Sciences, Journal of Social and Humanities, Canada: 278-283.

14. Malykhina I.O., Somina I.V., Moiseev V.V., Glagoltva N.N. 2017 Important aspects of forming and realization of region's innovation strategies. International Conference on Research Paradigsm Transformation in Social Sciences (RPTSS 2017): 1308-1314.

15. Nasir G.R., Titova I.N., Glotova A.S., Troshin A. 2019. Predictive models and scenarios of economic development of the region. Economic and Social Development Book of Proceedings:1143-1149.

\section{References}

1. Bruskone T.V. 2014. Formirovanie i realizaciya turistskogo potenciala regiona [Formation and realization of the region's tourism potential]. Abstract. dis. ... cand. econ. sciences. Saint-Petersbourg, 18.

2. Gareev I.F., Muhametova N.N. 2017. Kompleksnoe razvitie territorii_celi_resursi i pokazateli effektivnosti. [Comprehensive development of territories: goals, resources and performance indicators]. Russian entrepreneurship, 18(23): 3939-3952.

3. Kuznetsov B.T. 2014. Upravlenie investiciyami. [Investment management]. Moscow, Blagovest$\mathrm{V}, 425$.

4. Matveev Yu.V., Stepanova T.E., Matveev K.Yu. 2017. Regionalnoe razvitie kak innovacionnoinvesticionnii process institucionalnogo upravleniya. [Regional development as an innovation and investment process of institutional governance]. Creative economy. 11(5): 637-658.

5. Muhametova N.N. 2016. Territorialnii podhod $\mathrm{k}$ formirovaniyu konkurentnih preimuschestv regiona. [A territorial approach to building the region's competitive advantages]. Housing strategies. 3(3): 179192.

6. Svyatoho N.V. 2016. Konceptualnie osnovi issledovaniya turistskogo potenciala regiona. [The conceptual basis of research into the tourism potential of the region]. Teoriya i praktika upravleniya, 2: 30-35.

7. Seselkin A.I., Rassohina T.V. 2013. Analiz kriteriev ustoichivogo razvitiya turistskih destinacii. [Analysis of the criteria for sustainable development of tourist destinations]. Nauchno-prakticheskii jurnal «Vestnik RMAT». 2(8):28-33.

8. Stolyarova Z.V., Stolyarova V.A., Pango Tchapdo Sedoin. 2019. Nauka i tehnologii kak vajneishii faktor ekonomicheskogo razvitiya $\mathrm{v}$ usloviyah globalizacii. [Science and technologies as the main factor of economic development in terms of globalozation]. 6th International Conference Law, economy and management in modern ambience lemima, Univerzitet „Union - Nikola Tesla”, Beograd: 313-317.

9. Dankova Z.Y., Muzyleva E.S. 2017. Modeling of managerial processes in the conditions of innovative economy. Adavnces in Engineering Reeseach. (Actual Issues of Mechanical Engineering AIME 2017), 133: 148-155. 
10. Doroshenko Y.A., Somina I.V., Komissarov S.A. and Doroshenko S.Y. 2015. The Essence and Characteristics of Investment Processes in Small Innovative Enterprises. Asian Social Science 11(6):185-191

11. Doroshenko Y.A., Somina I.V., and Komissarov S.A. 2013. Sources of Financing and Innovative and Investment Activity of Small Enterprises. World Applied Sciences Journal 25(6): 975-982

12. Kupriyanov S.V., Troshin A.S., Sandy I.S., Stryabkova E.A. 2016. Investment process development: principles and characteristics. International Journal of Pharmacy and Technology, 8. (4): 24848 24855 .

13. Kupriyanov S.V., Stolyarova V.A., Stolyarova Z.V. 2015. The role of science as a factor of integration of countries in the context of globalization. Asian Social Sciences, Journal of Social and Humanities, Canada: 278-283.

14. Malykhina I.O., Somina I.V., Moiseev V.V., Glagoltva N.N. 2017 Important aspects of forming and realization of region's innovation strategies. International Conference on Research Paradigsm Transformation in Social Sciences (RPTSS 2017): 1308-1314.

15. Nasir G.R., Titova I.N., Glotova A.S., Troshin A. 2019. Predictive models and scenarios of economic development of the region. Economic and Social Development Book of Proceedings:1143-1149.

\section{Ссылка для цитирования статьи For citation}

Столярова В.А., Столярова 3.В., Трошин А.С. 2020. Методические подходы к оценке развития региона с позиции исследования уровня его туристского потенциала. Экономика. Информатика. 47 (2): 254-263. DOI: 10.18413/2687-0932-2020-47-2-254-263.

Stolyarova V.A., Stolyarova Z.V., Troshin A.S. 2020. Methodical approaches to the development of the region through the study of its tourist potential. Economics. Information technologies. 47 (2): 254-263 (in Russian). DOI: 10.18413/2687-0932-2020-47-2-254-263. 